\title{
The viral accelerated NF-KB pathway drives COVID-19-associated coagulopathy via excessive transcription of tissue factor and plasminogen activator inhibitor 1 - case report
}

Marco Leitzke ( $\nabla$ marco.leitzke@gmx.de)

HELIOS Kliniken GmbH https://orcid.org/0000-0001-5155-1978

Peter Oskar Dieter Schönknecht

Universitätsklinikum Leipzig: Universitatsklinikum Leipzig

Case report

Keywords: COVID-19-associated coagulopathy, plasminogen activator inhibitor 1, tissue factor, SARS-CoV-2, NF-kB pathway, vagal nerve stimulation

Posted Date: July 27 th, 2021

DOI: https://doi.org/10.21203/rs.3.rs-382537/v3

License: @ (i) This work is licensed under a Creative Commons Attribution 4.0 International License. Read Full License 


\section{Abstract}

Background The current COVID-19 pandemic creates new clinical challenges almost daily, especially in terms of individual prognoses, diagnostics involving newly discovered pathogenic mechanisms, and the appearance of SARS-CoV-2 mutations. In terms of the thromboembolic complications frequently occurring in COVID-19 patients, there is new evidence that pathognomonic COVID-19-associated coagulopathy (CAC) differs considerably from the coagulant malfunction of common disseminated intravascular coagulation. Thus, bleeding is a rare complication in the initial stages of the disease, whereas thrombotic formations can be seen autopticly in the vasculature of several organs. Therefore, it is speculated that most thromboembolic complications are thrombotic rather than embolic, and CAC is more likely to be a pro-coagulant form of coagulopathy. The reasons for these key differences have remained unknown until very recently. The relationship between SARS-CoV-2 infection and the virus-related acceleration of the transcriptional nuclear factor kappa B (NF-kB)-pathway, with the accompanied excessive downstream release of NF-KB-dependent proteins, is undisputed. Therefore, the roles of the NF-kB-transcribed anti-fibrinolytic plasminogen activator inhibitor (PAI 1) and NF-KB-dependent tissue factor (TF) have become worthy of attention. Inappropriate TF action results in enhanced fibrin clot formation, whereas overexpression of PAI 1 prevents appropriate fibrinolytic reactions. CAC is interpreted as critically contributing to overall COVID19 pathology and is most likely an independent risk factor for mortality.

Case report A 49-year-old male patient was admitted for initially non-specific signs of a previously detected SARS-CoV-2 infection. Despite antibiotic and antiinflammatory, anticoagulant such as respiratory-supporting therapy, respiratory and inflammatory parameters deteriorated continuously. The COVID-19 specific procoagulant hemostatic disarrangement deteriorated concordantly with the inflammatory parameters. Finally, a pulmonary arterial obstruction was detected, and an ultima ratio veno-pulmonary arterial extracorporeal membrane oxygenation (ECMO) was carried out, which required additional anticoagulatory management. The next day, multiple intracerebral bleeding led to the death of the patient.

Conclusions The usual anticoagulatory management is unlikely to avoid intravascular clot formation without developing severe bleeding complications. The ventilation-related acceleration of NF-KB pathway should be limited, as should procoagulatory blood flow interventions. In order to limit the excessive transcription of NF-KB-dependent procoagulant/anti-fibrinolytic proteins vagus nerve stimulation should be considered as a therapeutic tool.

\section{Background}

COVID-19 has become a threat to individual health, national and global health-care systems, and economic and social systems.

Recently, nuclear factor-KB (NF-kB) (see box I(1)) was shown to play a pivotal role in the pathogenesis of the pulmonary damage and systemic inflammation common to COVID-19(1). A transcriptional factorof pro-inflammatory cytokines (IL6, IL8, TNFa), NF-KB is excessively overexpressed by viral hijacking of its transcription-promoting pathway $(1-4)$.

After cellular invasion via ACE2 receptors(5), SARS-CoV-2 amplifies the action of the cellular IKB kinase complex (IKK)(2), which catalyzes the proteasomebased degradation of cytosolic inhibitors (IKBs)(6) of NF-KB subunits (p65, p50 or p52; c-Rel, RelA or RelB) leading, ultimately, to unrestricted subunit passage through the nuclear membrane and the excessive formation of mature NF-KB(2)(see box II(1)). This, in turn, promotes the uncontrolled downstream transcription of NF-KB-dependent proteins (i.e., SARS-CoV-2 and proinflammatory cytokines)(1) (Figure 1).

The physiological restraint mechanism of cellular NF-KB action is the vagally driven cholinergic anti-inflammatory pathway (CAP)(7-10). This pathway limits NF-KB activity via membrane-bound nicotinic acetylcholine receptors (a7nAChR), which, after coupling to vagally secreted acetylcholine (ACh), initiate blocking of NF-KB-mediated transcription(7-10). Thus, the balance between pro- and anti-inflammatory effects creates a health-preserving immune response to external assault(7-10). In severely ill patients, vagal signaling is critically compromised, leading to inappropriate inflammatory responses(1). This autonomic shift is also seen in COVID-19(1,11). Moreover, SARS-CoV-2 is suspected to bind not only to ACE2 receptors but also to nicotinic acetylcholine receptors (nAChRs)(12). Because a7nAChRs are a pivotal part of the anti-inflammatory reflex arc (involving CAP), virus-related a7nAChR impairment potentiates the NFKB pathway acceleration evoked by vagal dysfunction and viral hijacking (Figure 1).

In almost all COVID-19 cases, we see elevated coagulation parameters, such as increased d-dimer(13-16) and prolonged prothrombin time (PT)(14-17), as well as prolonged activated partial thromboplastin time $(\mathrm{aPTT})(14,15,17)$. Hence, disseminated intravascular clot formation can be observed(14, 15, 18-20) in critically ill COVID-19 patients, whereas incidences of significant hemorrhagic complications are rarely reported(18). Several specific aspects of COVID-19associated coagulopathy $(C A C)(17,19)$ differ from what we know about disseminated intravascular coagulation (DIC)(18). The most important differences between CAC and DIC are the elevated fibrinogen(14) serum levels, the activated complement system(21, 22), and increased concentrations of antiphospholipid antibodies(14) during CAC, compared with the lower fibrinogen concentrations, reduced complement system activity, and lower antiphospholipid antibody serum levels seen in DIC pathology(17). Both CAC and DIC share elevated d-dimer values, which reflect fibrinolytic activation in response to venous thromboembolism (VTE)(23). These specific coagulopathic changes in CAC and the high incidence of thromboembolic complications in COVID-19 have led to the proposed use of high d-dimer values as illness severity factors(24) and indicators of a poor prognosis in COVID-19 cases(25). The reasons for the differing specificity of CAC compared with DIC have remained unclear $(15,17,18,26,27)$ until recently.

In our recently published article, we described the importance of the accelerated NF-KB pathway in the pathology of SARS-CoV-2-evoked COVID-19(1). Here, we focus on the fact that procoagulant tissue factor $(\mathrm{TF})(26,28-30)$ and antifibrinolytic plasminogen activator inhibitor 1 (PAI 1$)(28,30,31)$ are transcribed in an NF-KB-dependent manner $(28,30)$. The promotional role of NF-KB in the transcription of two factors (that potently move the hemostatic balance towards clot formation and impaired fibrinolytic reaction) and the viral-induced, specifically accelerated NF-KB pathway are the first reasonable explanations for the specific coagulopathic pattern seen in COVID-19 (Fig. 1)(32, 33). 
The cytoplasmatic subunits (p65, p50 or p52, c-Rel, RelA or RelB) of NF-kB, the transcriptional factor of numerous cellular proteins, are bound by inhibitor proteins of NF-KB subunits (IKB) in the cytoplasm, guaranteeing the regulation of NF-KB production. Invasion of SARS-CoV-2 via the ACE 2 receptor amplifies the activity of the IKB kinase complex (IKK), which catalyzes the proteasome-driven proteolytic degradation of IKB. The liberated NF-KB subunits can now translocate to the nucleus unrestricted, where they form mature NF-KB. NF-KB binds to nuclear DNA to enhance virus replication and the synthesis and release of pro-inflammatory cytokines (i.e., IL 6, IL 8, TNF a) as well as procoagulant tissue factor (TF) and anti-fibrinolytic plasminogen activator inhibitor 1 (PAI 1). Vagally secreted acetylcholine (ACh) binds to $\alpha 7$ nicotinic acetylcholine receptors ( $\mathrm{a} 7 \mathrm{nAchRs)}$ ) at the cell surface and blocks NF-kB action, thereby controlling virus replication, cytokine release, and the synthesis of procoagulant/anti-fibrinolytic factors. Afferent vagal nerve stimulation leads to improved vagal representation in a hypersympathetic, imbalanced autonomic nervous system (ANS), which can reestablish the physiologically restrained NF-KB activity.

\section{Ventilation-derived oxygen and stretch collaborate with SARS-CoV-2 to activate the NF-KB pathway:}

In their review, Jacobson and Birukov (2009) pointed out that, in critically ill patients, mechanical ventilation with hyperoxic gas concentrations is often necessary to secure adequate oxygen delivery via an injured lung to the vital organs(34). Moreover, in most cases, the consolidated lung requires high peak pressure values, even with the use of low tidal volumes (LTVs) due to severely decreased pulmonary compliance(34). High peak pressures with concomitant pulmonary stretch stress together with hyperoxic gas mixtures also result in the activation of nf-KB(34), which is known to promote the transcription of PAl 1 and $\operatorname{TF}(30,35)$. Impaired alveolar membrane function combined with severe decreased pulmonal compliance are found in the COVID-19-affected lung(36). Thus, viral acceleration of the NF-KB pathway $(1,2)$, along with the almost unavoidable mechanical and hyperoxic stresses to pulmonary tissue, leads to enhanced NF-KB action. Through increased fibrin clot formation and severely impaired fibrinolytic potential, the concomitant extravascular activation of antifibrinolytic PAI 1 and procoagulant TF leads to micro- and macrovascular thrombosis(34). These, together with the NF-KB-driven enhancement of virus replication $(1,2)$ and further release of proinflammatory cytokines $(1,2,37)$, explain why this avalanche-like process is observed in critically ill coVID-19 cases.

\section{Thrombotic assault in lung and liver:}

In their recently published autoptic investigation of COVID-19 fatalities, Lax et al. (2020) described widespread occlusions within the pulmonal arterial vasculature and hepatic vessels, whereas the injury patterns in other parenchymatous organs were predominantly unrelated to malperfusion(19). They stated that these pulmonary arterial occlusions were of thrombotic instead of embolic origin(19). As in the case reported below, all cases presented by Lax et al. received anticoagulant or antiaggregant therapy or a combination of both(19). While in the report by Lax et al., patients received only prophylactic anticoagulant or antiaggregant therapy, every COVID-19 patient in our hospital is medicated with therapeutic anticoagulation from day one of admittance, including the case reported below. Pulmonary thrombotic damage was demonstrable in all samples $(n=11)$ reported by Lax et al. and ranged from focal to extensive(19). Although pulmonary infarction due to thrombosis occurred in only three of the investigated cases, the authors described the amount of thrombotic material in the pulmonary flow path as gross(19). Additionally, several authors have reported the association between COVID-19 and diffuse and gross clot formation in the branches of the pulmonary artery $(20,38-42)$. Although pulmonary coagulopathy with fibrin clot formation in the lungs due to NFKB-activated membrane-bound TF and PAI 1(30) is typical in infectious conditions, the specific SARS-CoV-2-related avalanche-like acceleration of the NF-KB pathway seems to influence the amount of enhanced fibrin clotting and fibrinolysis impairment.

In addition to the hypoxic damage caused by thrombosis, investigators have described a plethora of pathological changes, including edema, hyaline membrane, proliferation of pneumocytes and fibroblasts, macrophages, lymphocytes, plasma cells, neutrophils, and collagen, with a heterogeneous distribution $(19,20,43,44)$, which are summarized as diffuse alveolar damage (DAD)(19). The amount of thrombus consolidation is correlated with the duration of the disease(19). Thrombotic clots were detectable in small to mid-sized pulmonary arterial vessels, whose walls were infiltrated by neutrophils, and the adjacent lung tissue showed hemorrhaging and infarction(19). Even in one patient with grossly recognizable pulmonary infarct demarcation, Lax et al. (2020) considered the occlusion to be of thrombotic rather than embolic origin due to the completely thrombotic clot-filled lumen of the affected pulmonary arterial vessels(19). The absence of clot fixation to the arterial wall, as well as the fact that histological consolidation of some of the clots had not yet occurred, led the authors to estimate that these clots formed just a few hours(19) before death. The investigation by Lax et al. (2020) of hepatic tissue in COVID-19 fatalities showed there was massive hepatocyte necrosis in $73 \%$ of the cases from chronic congestion of single cells (predominantly pericentral) or a focal or panlobular pattern(19). Finally, in one case, central hepatic vein thrombosis was described(19). Moreover, other histological hepatic changes, such as steatosis (70\%), cholestasis with canalicular bile plugs (62\%), and portal changes (lymphocytic infiltrate, mild nuclear pleomorphism of cholangiocytes, and ductular proliferation with portal or incomplete septal fibrosis) were seen in nine (82\%) of their subjects(19). 
NF-KB (nuclear factor kappa-light-chainenhancer of activated $B$ cells) is a protein of complex structure that controls DNA transcription, cytokine production and cellular survival. NF-kB can be found in almost all animal cell types and promotes cellular reaction to stimuli such as stress, cytokines, free radicals, heavy metals, ultraviolet irradiation, and microbial antigens. NF-KB plays a principal role in regulating the immune response to infectious assault. Regulation disorders of NF-KB have been linked to viral infection, septic shock, hyperinflammatory and autoimmune diseases, cancer, and disturbed immune maturation. memory. box I: Transcriptional factor nf- $\mathrm{kB}$ - the key to pathology

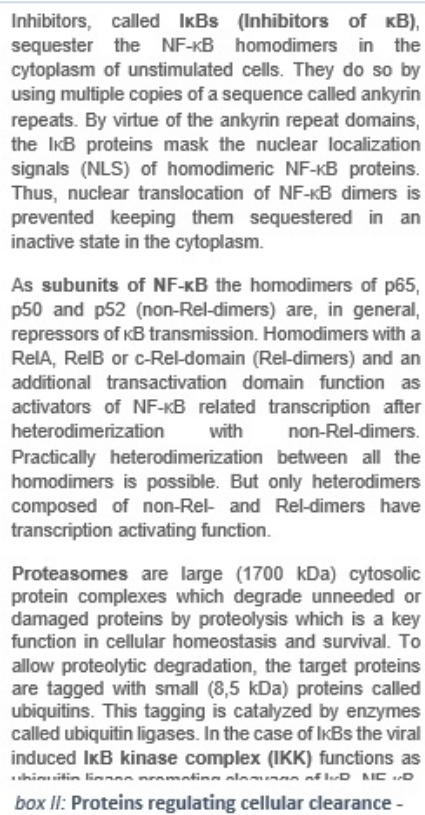

\section{Case Report}

On December 22, 2020, a 49-year-old male patient was admitted to our hospital with initial signs of fever, a nonproductive cough, and limb pain for 6 days. An outpatient ward PCR test revealed a case of SARS-CoV-2 infection. Since the day before admittance, the patient had felt severe dyspnea. Despite two episodes of transitory ischemic cerebral attacks leading to prophylactic treatment with acetylsalicylacid, and a former smoking history, no accompanying medical condition or prescribed medication was detectable.

Initially the patient showed nonspecific symptoms, including an oxygen saturation of $75 \%$ on pulse oximetry under spontaneous breathing of air, as well as stable cardiocirculatory conditions and mild fever $\left(38.3^{\circ} \mathrm{C}\right)$. An electrocardiogram revealed no pathological findings.

The first chest x-ray showed a pronounced homogenous, partly stained decrease in transparency on both sides with well delimited diaphragmatic thighs, no evidence of pleural effusion, and standard caliber thoracal vasculature with a normal heart silhouette (Fig. 2).

The initially sufficient oxygen supply of $2 \mathrm{~L}$ per minute had to be increased rapidly to up to $6 \mathrm{~L}$ per minute. Treatment with dexamethasone ( $6 \mathrm{mg} /$ day) and antibiotics (ampicillin/sulbactam) due to heightened serological inflammation signs (Table 1$)$ was started. Because oxygen saturation did not improve $\left(\mathrm{SpO}_{2}\right.$ below $80 \%$ ), the patient was transferred to our ICU the following day.

In the ICU, we applied intermediate noninvasive mechanical ventilation (CPAP/ASB) with equally intermediate prone positioning. This initially led to improvements in both respiratory function and serological inflammation signs (Table 1). From day four of treatment, respiratory function worsened, and serological inflammation signs began to re-emerge. We escalated the antibiotic regime (piperacillin/tazobactam) and gradually increased $\mathrm{FiO}_{2}$; meanwhile the patient needed continuous noninvasive augmented respiratory ventilation (CPAP/ASB). In the following period, we saw improvements in infection signs and stable respiratory conditions that made short interruptions of mechanical ventilation possible. On day 13 , the inflammatory parameters again increased, leading us to further escalate antibiotic treatment (meropenem). Ventilatory support became insufficient on day 13 , thus we decided to intubate for controlled ventilation (Fig. 3). During the intubation procedure, the patient experienced a low flow phase, which required the application of epinephrin and two single chest compressions. After cardiocirculatory stabilization, the patient was moved to the prone position, and ventilatory parameters $\left(\mathrm{FiO}_{2}\right.$, peak pressure) $\mathrm{could}$ be gradually decreased. Because of the unimpaired renal function, the patient received therapeutic anticoagulation with low molecular weight heparin (LWMH; enoxoparin sodium $80 \mathrm{mg}$ two times daily) over the whole treatment period. Because of sedation compensation, the patient received low dosage norepinephrine, which could be reduced further over the days following intubation. 
This x-ray picture corresponded to a sharp increase in clinical severity. In particular, the respiratory situation was no longer manageable with oxygen supply or noninvasive ventilation strategies, and we were forced to perform an intubation with controlled mechanical ventilation.

Considering the progressing severity of the illness, the overall good prognosis of the young patient, and the absence of extracorporeal membrane oxygenation (ECMO) facilities in our hospital, we decided to transfer the patient to a hospital with ECMO capacity on day 16.

Until the transfer, the ventilation parameters had to be increased to $65 \%$ for FiO2, 40 mbar for peak pressure, and 10 mbar for positive end expiratory pressure.

At the hospital with ECMO provision, the first transthoracic echocardiography (TTE) revealed severe right heart burdening. Under the suspicion of a pulmonary arterial embolic event, a thoracic CT with radiocontrast agent was performed (Fig. 4). This showed a central lymphadenopathy in addition to the commonly described signs of COVID-19 pneumonia (according to the RSNA consensus 2020)(45). Moreover, there was evidence of bilateral central pulmonary arterial embolism with consecutive closure of the segmental arteries plus distinct signs of right heart burdening with deviating ventricular septum and d-shape of the left ventricle.

After an interdisciplinary consultation, the decision to proceed with an ultima ratio ECMO implantation was made, and the procedure was performed immediately and without complication. Venopulmonary arterial ECMO was performed that required anticoagulant management with high molecular weight heparin (HMWH). Additionally, the salvation of a gross thrombus from the left pulmonary artery was possible.

Afterwards, the patient was retransferred to the ICU, where the ventilation parameters were deescalated to lung-protective ventilation under therapeutic anticoagulation and ECMO. Serological coagulation parameters were observed frequently, and blood transfusion was performed by indication and under consideration of present antibodies.

Table 1

Courses of laboratory data for inflammation parameters, such as leukocytes, procalcitonin (PCT), and c-reactive protein (CRP), in comparison to the coagula including d-dimer, activated thromboplastin time (aPTT), Quick (TZW), antithrombin activity, Quick international normalized ratio (INR), and fibrinogen. The co

\begin{tabular}{|c|c|c|c|c|c|c|c|c|c|c|c|c|c|c|c|c|c|}
\hline day & 1 & 2 & 3 & 4 & 5 & 6 & 7 & 8 & 9 & 10 & 11 & 12 & 13 & 14 & 15 & 16 & 17 \\
\hline $\begin{array}{l}\text { d-dimer } \\
(\mu \mathrm{g} / \mathrm{ml})\end{array}$ & 1.09 & 0.73 & & 1.08 & 1.06 & 0.81 & 0.97 & & & & & & $>4$ & 3.90 & & & $>4$ \\
\hline aPTT (s) & 32.2 & 31.5 & 32.3 & 32.6 & 29.6 & 29.2 & 30.0 & 32.2 & & 29.2 & 31.0 & 31.4 & 36.4 & 39.7 & 39.7 & 30.0 & $3 i$ \\
\hline TZW (\%) & 108 & 103 & 110 & 107 & 105 & 92 & 86 & 81 & & 79 & 84 & 75 & 64 & 51 & 82 & 81 & $1 C$ \\
\hline $\begin{array}{l}\text { Antithrombin } \\
(\%)\end{array}$ & & 113 & & & & & & & & & & & & & & & \\
\hline INR & 1.0 & & 0.9 & 1.0 & 1.0 & 1.1 & 1.1 & 1.2 & & 1.2 & 1.1 & 1.2 & 1.4 & 1.6 & 1.1 & 1.2 & $1 . !$ \\
\hline $\begin{array}{l}\text { fibrinogen } \\
(\mathrm{g} / \mathrm{l})\end{array}$ & & & & 7.5 & 7.9 & 6.9 & 8.3 & & & & & & 8.2 & 9.2 & & & 6 \\
\hline $\begin{array}{l}\text { Leucocytes } \\
\text { (Gpt/I) }\end{array}$ & 6.9 & 7.4 & 9.2 & 9.7 & 11.1 & 12.4 & 13.0 & 13.6 & 13.4 & 13.2 & 16.5 & 19.6 & 30.8 & 35.9 & 23.4 & 18.1 & 37 \\
\hline РCT $(\mu \mathrm{g} / \mathrm{l})$ & 0.13 & 0.13 & & 0.13 & 0.10 & 0.10 & 0.12 & 0.30 & 0.34 & & 0.23 & 0.20 & 0.25 & 0.41 & 0.24 & 0.20 & 0. \\
\hline CRP (mg/l) & 118.2 & 90.5 & & 119.1 & 145.0 & 78.1 & 114.3 & 185.7 & 196.7 & & 72.2 & 88.9 & 215.2 & 261.3 & 175.2 & 177.4 & $1 \angle$ \\
\hline
\end{tabular}

The next day, the patient had a right-sided wide and fixed pupil, which had not been seen in previous frequently performed examinations. An emergency skull CT scan showed multiple intracerebral bleeds together with a global edema, a midline shift, and the initial signs of acute compression of the brain stem (Fig.

5). The immediate neurosurgeon declared the prognosis to be infaust because of a lack of therapeutic options.

The relatives were immediately informed of the acute worsening followed by a change in the therapeutical goal to palliation, which was performed sufficiently until the death of the patient on January 8, 2021.

After a condoling report to the relatives, they did not agree to an autopsy.

\section{Discussion}

Procoagulant disarrangements in the hemostatic balance between fibrin clot formation and fibrinolytic action are obviously important contributors to overall COVID-19 pathology. In severe cases, they are probably an independent risk factor for fatality $(19,25,46)$. Attempting to control this procoagulant hemostatic catastrophe with the application of antithrombin III (ATIII) enhancers or factor Xa inhibitors, i.e., HMWH and LMWH, respectively, as we currently do, seems to have no real efficiency $(19,47)$. With regards to the reported case, the recently proposed use of thrombolytic therapeutic regimes(48) has to be deemed equally as risky.

In our demonstrated case, we saw severe thromboembolic occlusion of the bilateral, central pulmonary arterial branches, despite therapeutic anticoagulant therapy. At the same time, the patient underwent a multi-localized intracerebral hemorrhage event. This evidence seems to show that a gap between 
insufficient anticoagulation with clot formation and severe bleeding in CAC does not exist.

Until recent days, our search for solutions to combat COVID-19 focused mainly on the hyper-inflammatory aspects of this fateful disease with its elusive pathological pattern(1). The herein described specific mechanisms of COVID-19-related coagulopathy and the reported case illustrate that disseminated hypoxic organ dysfunction may be explained not only by hypoxemia from severe pulmonary dysfunction but also by micro- and macrovascular thrombotic vessel occlusion $(13,14)$. Thus, microvascular thrombotic damage is observed in the tissues of the heart, liver, kidneys, gastrointestinal tract, skin, adrenal gland, prostate(13), brain, and limbs(14). The described multi-focal thrombotic occlusions are a critical part of the multi-organ pathology observed in severe COVID-19 cases. The acceleration of the NF-KB pathway due to viral hijacking of ubiquitination machinery(49), ventilation-associated NF-KB enhancement(30, $34,35)$, and the pathognomonic impairment of vagal signaling(1) seems to be the central reason for the highly activated thrombogenesis (TF). This, in combination with inappropriate antifibrinolytic action (PAI 1), causes CAC, which ultimately leads to thrombotic organ injury. The reasons behind the similarly enhanced concentrations of prothrombotic antiphospholipid antibodies $(14,18)$ and the facilitation of clot formation by complement system(21, 22) activation, as well as their impact on CAC, remain to be investigated.

The interaction between the virus-related acceleration of the NF-KB pathway and ventilation-evoked activation of NF-KB, both of which lead to the severe activation of coagulation (TF) and severe impairment of fibrinolysis (PAI 1) as well as enhanced virus replication and cytokine distribution, presents a profound dilemma during the treatment of critically ill COVID-19 patients. The key to resolving this conflict seems to be controlling NF-KB activity. This is, as previously described, a domain of vagal nerve signaling $(1,7,9,50)$.

The newly discovered thrombotic complications in connection with several vaccines(51) seem to be more COVID-19 related, than vaccine-specific. Therefore, CAC must be considered a part of the hemostatic dysfunction due to vaccination.

Thus, an unrecognized SARS-CoV-2 infection before vaccination could have led to additional acceleration of NF-KB evoked prothrombotic and antifibrinolytic hemostatic disarrangement. Likewise, the specific immune reaction to the vaccine may have resulted in NF-KB activation with its hemostatic consequences.

\section{Conclusions}

Considering the aforementioned hemostatic pathological constellation in COVID-19 and the current therapeutic options, we should restrict ventilation parameters(52) to a degree that guaranties a sufficient oxygen supply and decarboxylation for vital organs, without exceeding a certain blood oxygen partial pressure limit (e.g., $60 \mathrm{mmHg}$ ). This would maintain oxygenation while minimizing further ventilation-related damage to the lungs(52) and coagulant system(34).

Additionally, in relation to hyper-coagulant hemostasis in COVID-19 patients and the limited treatments available to counteract clot formation, any additional procoagulant intervention (i.e., central venous catheters) should be applied prudently and restrictively.

Because controlling the activity of NF-KB is the only causal therapeutic option, and this can be physiologically promoted by vagus nerve signaling(7, 9), vagus nerve stimulation (VNS) is proposed as a serious candidate for the treatment of severe COVID-19 cases(1). Indeed, Guarini et al. (2003) showed that VNS is able to blunt inappropriate NF-KB activation(53).

In light of the described relationships between SARS-CoV-2 infection (COVID-19), the NF-KB-dependency of COVID-19-related hemostatic disarrangements, and NF-KB promotion of virus replication and cytokine distribution, we strongly believe that VNS must be taken into consideration as a viable option for the treatment of this difficult to manage disease.

\section{List Of Abbreviations}

ACE2

ACE2 is an enzyme which lowers blood pressure by catalyzing the hydrolysis of angiotensin II (a vasoconstricting peptide) into angiotensin (a vasodilating peptide). ACE2 is attached to the cell membranes of cells in the lungs, arteries, heart, kidney and intestines.

$4,5,20$

\section{CAP}

The cholinergic anti-inflammatory pathway is involved in the regulation of the innate immune response to injury, pathogenic assault, and ischaemic injury. It is the efferent arc of the inflammatory reflex, the vagally driven neural circuit controlling cytokin release via acetylcholin coupling to nicotinergic

acetylcholinreceptors. $\quad 4,5$

\section{COVID-19}

Coronavirus disease 2019 is a highly contagious disease caused by severe acute respiratory syndrome virus 2019 (SARS-CoV-2) with variable symptoms including fever, cough, loss of smell and breathing difficulties, which in severe cases improve up to pneumonia with severe impairment of respirators function and multiple organ failure (MOF).

$1,2,3,5,6,7,9,10,11,14,15,16,17,18,19,20,21,22,23$

IKK

The IKB kinase is a complex that is involved in promoting the cellular response to inflammation. 4, 8 
IL 6

Interleukin 6 is an important mediator of fever and of the acute phase response and is secreted by macrophages in response to specific microbial molecules, referred to as pathogen-associated molecular patterns (PAMPs) 8

IL 8

Interleukin 8 is a chemokine secreted by macrophages and other cells, such as epithelial cells, airway smooth muscle cells, and endothelial cells. IL-8 acts as a chemokine, encouraging immune cells to migrate. 8

NF-KB

nuclear factor kappa-light-chain-enhancer of activated B cells) is a protein of complex structure that controls DNA transcription, cytokine production and cellular survival. 1, 2, 3, 4, 5, 6, 7, 8, 9, 10, 17, 18, 19, 20, 22

RSNA

Radiological Society of North America

$14,15,24$

SARS-CoV-2

Severe acute respiratory syndrome coronavirus 2 is the virus causing coronavirus disease 2019 (COVID-19), the infectious disease responsible for the current pandemic. $1,2,4,5,6,7,8,10,11,19,20,21,22$

TNF a

Tumor necrosis factor alpha is a cytokine that promotes systemic inflammation and induces the acute phase reaction. It is mainly produced by activated macrophages but can be produced by many other cell types. 8

a7nAChR

The nicotinergic alpha7 acetylcholin receptor is involved in restriction of cytokin liberation and inflammation control, as well as long-term memory. It consists of pentamerically composed a7 subunitis and is part of the cholinergic driven neuromudulation.

5

\section{Declarations}

\section{Ethics approval and consent to participate}

not applicable

\section{Consent for publication}

not applicable

\section{Availability of data and material}

The dataset of the reported case are not published for preserving privacy of the patient and are stored and available in an anonymized fashion from the corresponding author on reasonable request.

\section{Competing interests}

Marco Leitzke and Oskar Dieter Peter Schönknecht report no financial and no non-financial conflict of interest.

\section{Funding}

The authors received no financial support for the research, authorship, and/or publication of this article.

\section{Authors' contributions}

ML drafted the manuscript, analyzed the data and has been investigating for several years in the field of modulation of autonomic balance disorders with vagal nerve stimulation.

ODPS helped to draft and revised the manuscript.

All authors read and approved the final manuscript.

\section{Acknowledgements}

We thank Suzanne Leech, Ph.D., from Edanz Group (https://en-author-services.edanz.com/ac) for editing a draft of this manuscript. 
We thank Dr. Joao-Carlos Correia for providing the data from the collaborating hospital (heart center Leipzig).

Many thanks to Frank Jabin for the design of the figures.

\section{References}

1. Leitzke M, Stefanovic D, Meyer J-J, Schimpf S, Schönknecht P. Autonomic balance determines the severity of COVID-19 courses. Bioelectron Med. 2020 Dec;6(1):22.

2. Poppe M, Wittig S, Jurida L, Bartkuhn M, Wilhelm J, Müller H, et al. The NF-kB-dependent and -independent transcriptome and chromatin landscapes of human coronavirus 229E-infected cells. Enjuanes L, editor. PLOS Pathog. 2017 Mar 29;13(3):e1006286.

3. Kandasamy M. NF-KB signalling as a pharmacological target in COVID-19: potential roles for IKK $\beta$ inhibitors. Naunyn Schmiedebergs Arch Pharmacol. 2021 Mar;394(3):561-7.

4. Liao Q-J, Ye L-B, Timani KA, Zeng Y-C, She Y-L, Ye L, et al. Activation of NF-kappaB by the Full-length Nucleocapsid Protein of the SARS Coronavirus. Acta Biochim Biophys Sin. 2005 Sep;37(9):607-12.

5. Hoffmann M, Kleine-Weber H, Schroeder S, Krüger N, Herrler T, Erichsen S, et al. SARS-CoV-2 Cell Entry Depends on ACE2 and TMPRSS2 and Is Blocked by a Clinically Proven Protease Inhibitor. Cell. 2020 Apr;181(2):271-280.e8.

6. Brücher BLDM, Lang F, Jamall IS. NF- $\kappa$ B signaling and crosstalk during carcinogenesis. Bandapalli OR, editor. 4open. 2019;2:13.

7. Tracey KJ. Physiology and immunology of the cholinergic antiinflammatory pathway. J Clin Invest. 2007 Feb 1;117(2):289-96.

8. Tracey KJ. The inflammatory reflex. Nature. 2002 Dec 19;420(6917):853-9.

9. Borovikova LV, Ivanova S, Zhang M, Yang H, Botchkina GI, Watkins LR, et al. Vagus nerve stimulation attenuates the systemic inflammatory response to endotoxin. Nature. 2000 May 25;405(6785):458-62.

10. Leitzke M. Afferent vagal stimulation via gastric electrical stimulation alters sympathetic-vagal balance in domestic pigs - a pilot trial. J Biol Regul Homeost AGENTS [Internet]. 2021 Feb 28 [cited 2021 Feb 6];35(1). Available from: https://doi.org/10.23812/20-527-A

11. Lim S, Bae JH, Kwon H-S, Nauck MA. Reply to: Autonomic dyshomeostasis in patients with diabetes mellitus during COVID-19. Nat Rev Endocrinol [Internet]. 2021 Jan 18 [cited 2021 Jan 22]; Available from: http://www.nature.com/articles/s41574-021-00467-4

12. Changeux J-P, Amoura Z, Rey FA, Miyara M. A nicotinic hypothesis for Covid-19 with preventive and therapeutic implications. C R Biol. 2020 Jun $5 ; 343(1): 33-9$.

13. Polak SB, Van Gool IC, Cohen D, von der Thüsen JH, van Paassen J. A systematic review of pathological findings in COVID-19: a pathophysiological timeline and possible mechanisms of disease progression. Mod Pathol. 2020 Nov;33(11):2128-38.

14. Zhang Y, Xiao M, Zhang S, Xia P, Cao W, Jiang W, et al. Coagulopathy and Antiphospholipid Antibodies in Patients with Covid-19. N Engl J Med. 2020 Apr 23;382(17):e38.

15. Kander T. Coagulation disorder in COVID-19. Lancet Haematol. 2020 Sep;7(9):e630-2.

16. Liao $\mathrm{D}$, Zhou F, Luo L, Xu M, Wang H, Xia J, et al. Haematological characteristics and risk factors in the classification and prognosis evaluation of COVID-19: a retrospective cohort study. Lancet Haematol. 2020 Sep;7(9):e671-8.

17. Iba T, Levy JH, Connors JM, Warkentin TE, Thachil J, Levi M. The unique characteristics of COVID-19 coagulopathy. Crit Care. 2020 Dec;24(1):360.

18. Iba T, Levy JH, Levi M, Thachil J. Coagulopathy in COVID-19. J Thromb Haemost. 2020 Sep;18(9):2103-9.

19. Lax SF, Skok K, Zechner P, Kessler HH, Kaufmann N, Koelblinger C, et al. Pulmonary Arterial Thrombosis in COVID-19 With Fatal Outcome: Results From a Prospective, Single-Center, Clinicopathologic Case Series. Ann Intern Med. 2020 Sep 1;173(5):350-61.

20. Edler C, Schröder AS, Aepfelbacher M, Fitzek A, Heinemann A, Heinrich F, et al. Dying with SARS-CoV-2 infection-an autopsy study of the first consecutive 80 cases in Hamburg, Germany. Int J Legal Med. 2020 Jul;134(4):1275-84.

21. Song W-C, FitzGerald GA. COVID-19, microangiopathy, hemostatic activation, and complement. J Clin Invest. 2020 Aug 3;130(8):3950-3.

22. Gralinski LE, Sheahan TP, Morrison TE, Menachery VD, Jensen K, Leist SR, et al. Complement Activation Contributes to Severe Acute Respiratory Syndrome Coronavirus Pathogenesis. mBio. 2018 Oct 9;9(5).

23. Schutte T, Thijs A, Smulders YM. Never ignore extremely elevated D-dimer levels: they are specific for serious illness. Neth J Med. 2016 Dec;74(10):443-8. 
24. Guan W, Ni Z, Hu Y, Liang W, Ou C, He J, et al. Clinical Characteristics of Coronavirus Disease 2019 in China. N Engl J Med. 2020 Apr 30;382(18):1708-20.

25. Tang N, Li D, Wang X, Sun Z. Abnormal coagulation parameters are associated with poor prognosis in patients with novel coronavirus pneumonia. J Thromb Haemost. 2020 Apr;18(4):844-7.

26. Geng J-G, Wang J-G, Mackman N, Slungaard A, Huo Y, Key NS. Regulation of Tissue Factor by NF-kB Transcription Factor p50 Is Essential for the Pathogeneses of Deep Vein Thrombosis and Arterial Restenosis. Blood. 2006 Nov 16;108(11):1458-1458.

27. Leentjens J, van Haaps TF, Wessels PF, Schutgens REG, Middeldorp S. COVID-19-associated coagulopathy and antithrombotic agents-lessons after 1 year. Lancet Haematol. 2021 Apr;S2352302621001058.

28. Rainer de Martin, Hoeth M, Hofer-Warbinek R, Schmid JA. The Transcription Factor NF-kB and the Regulation of Vascular Cell Function. Arterioscler Thromb Vasc Biol [Internet]. 2000 Nov [cited 2021 Jan 15];20(11). Available from: https://www.ahajournals.org/doi/10.1161/01.ATV.20.11.e83

29. Parry GCN, Mackman N. Transcriptional Regulation of Tissue Factor Expression in Human Endothelial Cells. Arterioscler Thromb Vasc Biol. 1995 May;15(5):612-21.

30. Nieuwenhuizen L, de Groot PG, Grutters JC, Biesma DH. A review of pulmonary coagulopathy in acute lung injury, acute respiratory distress syndrome and pneumonia. Eur J Haematol. 2009 Jun;82(6):413-25.

31. Hosokawa S, Haraguchi G, Sasaki A, Arai H, Muto S, Itai A, et al. Pathophysiological roles of nuclear factor kappaB (NF-kB) in pulmonary arterial hypertension: effects of synthetic selective NF-kB inhibitor IMD-0354. Cardiovasc Res. 2013 Jul 1;99(1):35-43.

32. Khan SS. The Central Role of Plasminogen Activator Inhibitor-1 in COVID-19: Thrombosis and Beyond. Am J Respir Cell Mol Biol. 2021 Jun 4;

33. Cañas CA, Cañas F, Bautista-Vargas M, Bonilla-Abadía F. Role of Tissue Factor in the Pathogenesis of COVID-19 and the Possible Ways to Inhibit It. Clin Appl Thromb Off J Int Acad Clin Appl Thromb. 2021 Dec;27:10760296211003984.

34. Jacobson JR, Birukov KG. Activation of NFkB and coagulation in lung injury by hyperoxia and excessive mechanical ventilation: one more reason "low and slow" is the way to go? Transl Res. 2009 Nov;154(5):219-21.

35. Liu Y-Y, Liao S-K, Huang C-C, Tsai Y-H, Quinn DA, Li L-F. Role for nuclear factor-KB in augmented lung injury because of interaction between hyperoxia and high stretch ventilation. Transl Res. 2009 Nov;154(5):228-40.

36. Batah SS, Fabro AT. Pulmonary pathology of ARDS in COVID-19: A pathological review for clinicians. Respir Med. 2021 Jan;176:106239.

37. Dosch SF, Mahajan SD, Collins AR. SARS coronavirus spike protein-induced innate immune response occurs via activation of the NF-KB pathway in human monocyte macrophages in vitro. Virus Res. 2009 Jun;142(1-2):19-27.

38. Grimes Z, Bryce C, Sordillo EM, Gordon RE, Reidy J, Paniz Mondolfi AE, et al. Fatal Pulmonary Thromboembolism in SARS-CoV-2-Infection. Cardiovasc Pathol. 2020 Sep;48:107227.

39. Konopka KE, Wilson A, Myers JL. Postmortem Lung Findings in a Patient With Asthma and Coronavirus Disease 2019. Chest. 2020 Sep;158(3):e99101.

40. Bryce C, Grimes Z, Pujadas E, Ahuja S, Beasley MB, Albrecht R, et al. Pathophysiology of SARS-CoV-2: targeting of endothelial cells renders a complex disease with thrombotic microangiopathy and aberrant immune response. The Mount Sinai COVID-19 autopsy experience [Internet]. medRxiv; 2020. Available from: https://europepmc.org/article/PPR/PPR165963

41. Remmelink M, De Mendonça R, D'Haene N, De Clercq S, Verocq C, Lebrun L, et al. Unspecific <em>post-mortem</em> findings despite multiorgan viral spread in COVID-19 patients. medRxiv. 2020 Jan 1;2020.05.27.20114363.

42. Burkhard-Koren NM, Haberecker M, Maccio U, Ruschitzka F, Schuepbach RA, Zinkernagel AS, et al. Higher prevalence of pulmonary macrothrombi in SARS-CoV -2 than in influenza A: autopsy results from 'Spanish flu' 1918/1919 in Switzerland to Coronavirus disease 2019. J Pathol Clin Res. 2020 Nov 13;cjp2.189.

43. Lacy JM, Brooks EG, Akers J, Armstrong D, Decker L, Gonzalez A, et al. COVID-19: Postmortem Diagnostic and Biosafety Considerations. Am J Forensic Med Pathol. 2020 Sep;41(3):143-51.

44. Bradley BT, Maioli H, Johnston R, Chaudhry I, Fink SL, Xu H, et al. Histopathology and ultrastructural findings of fatal COVID-19 infections in Washington State: a case series. The Lancet. 2020 Aug;396(10247):320-32.

45. Foust AM, Phillips GS, Chu WC, Daltro P, Das KM, Garcia-Peña P, et al. International Expert Consensus Statement on Chest Imaging in Pediatric COVID19 Patient Management: Imaging Findings, Imaging Study Reporting, and Imaging Study Recommendations. Radiol Cardiothorac Imaging. 2020 Apr

1;2(2):e200214. 
46. Wichmann D, Sperhake J-P, Lütgehetmann M, Steurer S, Edler C, Heinemann A, et al. Autopsy Findings and Venous Thromboembolism in Patients With COVID-19: A Prospective Cohort Study. Ann Intern Med. 2020 Aug 18;173(4):268-77.

47. Barrett CD, Moore HB, Yaffe MB, Moore EE. ISTH interim guidance on recognition and management of coagulopathy in COVID-19: A comment. J Thromb Haemost JTH. 2020 Aug;18(8):2060-3.

48. Wang J, Hajizadeh N, Moore EE, McIntyre RC, Moore PK, Veress LA, et al. Tissue plasminogen activator (tPA) treatment for COVID-19 associated acute respiratory distress syndrome (ARDS): A case series. J Thromb Haemost. 2020 Jul;18(7):1752-5.

49. Taylor RT, Best SM. Assessing ubiquitination of viral proteins: Lessons from flavivirus NS5. Methods San Diego Calif. 2011 Oct;55(2):166-71.

50. Bonaz B, Sinniger V, Pellissier S. Vagal tone: effects on sensitivity, motility, and inflammation. Neurogastroenterol Motil. 2016 Apr;28(4):455-62.

51. Schultz NH, Sørvoll IH, Michelsen AE, Munthe LA, Lund-Johansen F, Ahlen MT, et al. Thrombosis and Thrombocytopenia after ChAdOx1 nCoV-19 Vaccination. N Engl J Med. 2021 Apr 9;NEJMoa2104882.

52. Gattinoni L, Coppola S, Cressoni M, Busana M, Rossi S, Chiumello D. COVID-19 Does Not Lead to a "Typical" Acute Respiratory Distress Syndrome. Am J Respir Crit Care Med. 2020 May 15;201(10):1299-300.

53. Guarini S, Altavilla D, Cainazzo M-M, Giuliani D, Bigiani A, Marini H, et al. Efferent vagal fibre stimulation blunts nuclear factor-kappaB activation and protects against hypovolemic hemorrhagic shock. Circulation. 2003 Mar 4;107(8):1189-94.

\section{Figures}

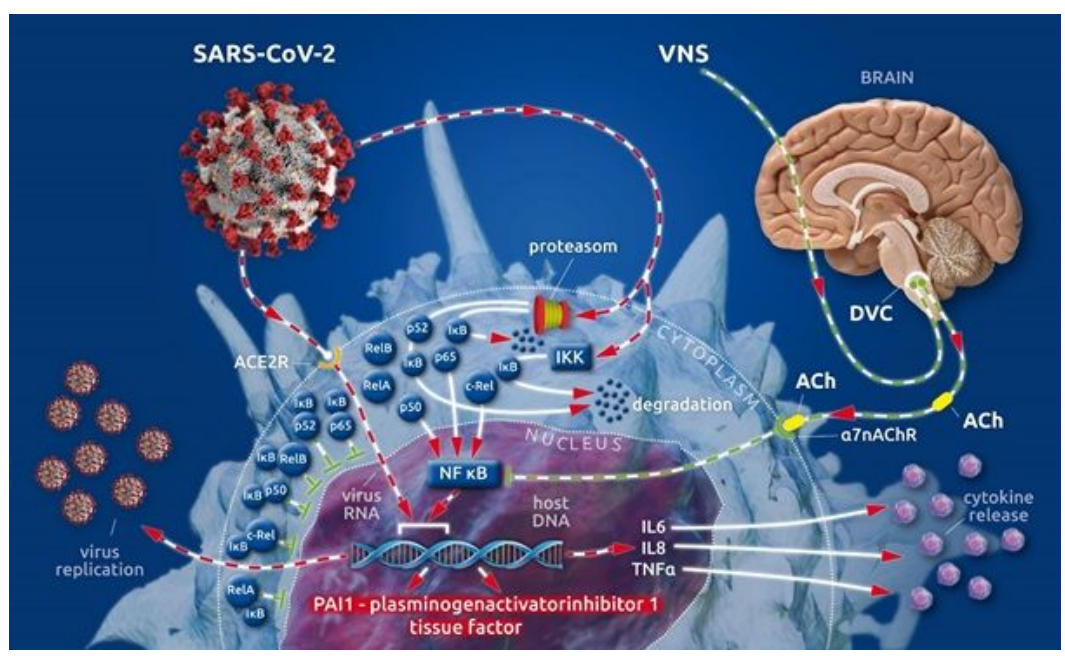

Figure 1

(Key Figure) Cellular viral (SARS-CoV-2) invasion involving viral hijacking and amplification of the nuclear factor kappa B (NF-kB) pathway for viral replication with the additional excessive release of pro-inflammatory cytokines as well as plasminogen activator inhibitor 1 and tissue factor 


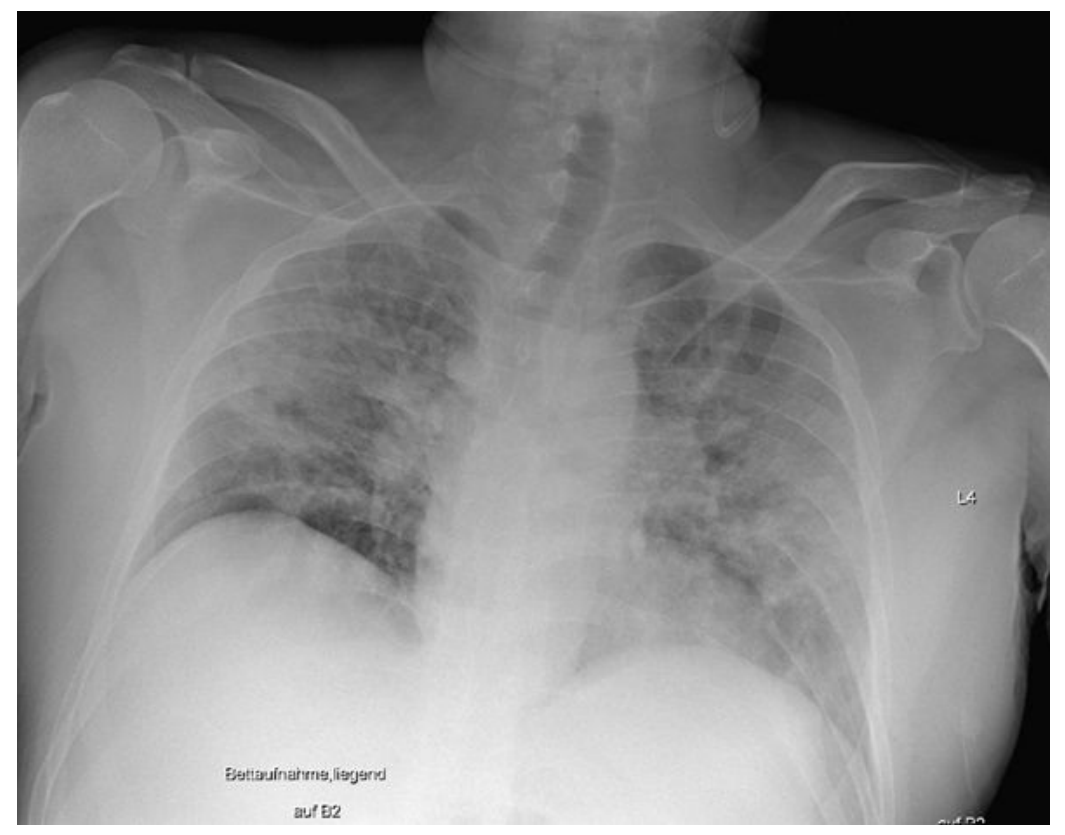

\section{Figure 2}

Initial chest x-ray: pronounced partly stained regions of impaired transparency on both sides, particularly in the middle fields, were observed. Overall slight inspirational hold. Both diaphragmatic thighs were clearly definable. There was no evidence for pleural effusion. With regard to definition, the vascular structures were of standard caliber, and the cordial silhouette was not broadened. This x-ray picture displays the initial clinical situation, which was sufficiently treatable with oxygen supply (up to $6 \mathrm{l} / \mathrm{min}$ ) and intermediate ventilatory support (NIV/CPAP/ASB).

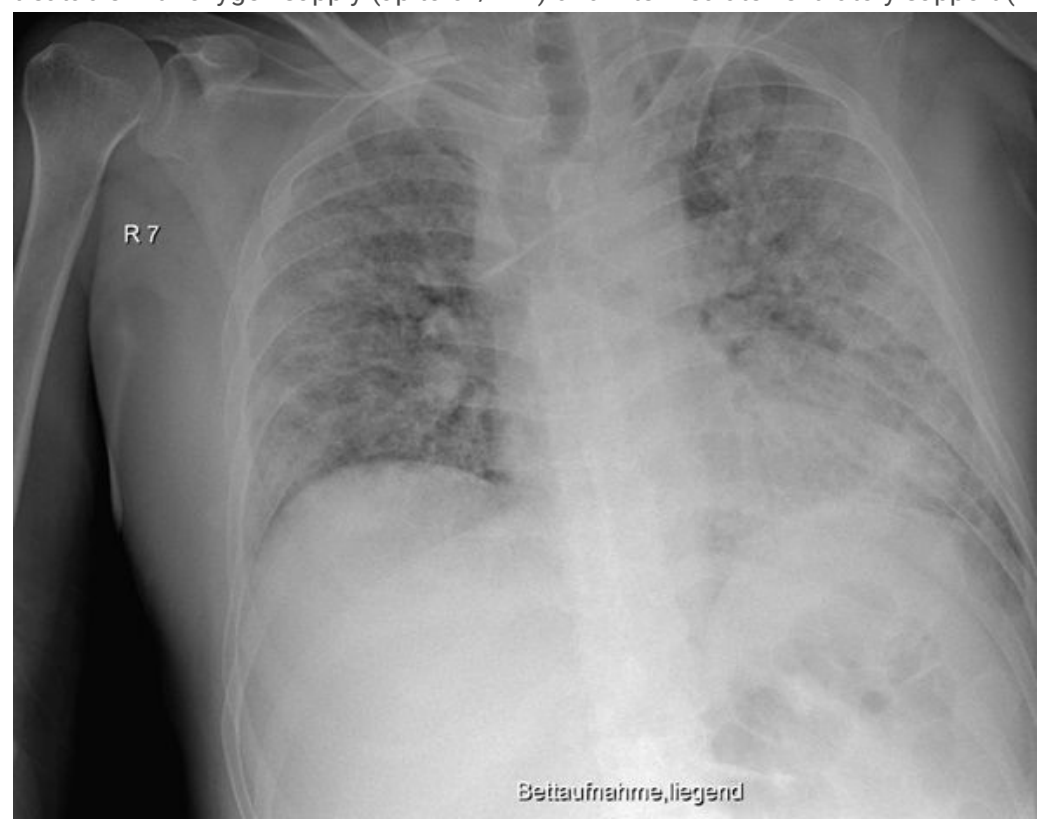

\section{Figure 3}

Chest x-ray showing worsening signs on day 13 , before intubation: compared with the preliminary examination, there were progressive peripherally pronounced bilateral infiltrations. For differential diagnostics, a mixed picture of infiltrates and pulmonary congestion must be taken into consideration. New: left-sided jugular central venous catheter with inconspicuous projection to the superior vena cava. Everything else remained unchanged compared with the preliminary examination. This x-ray picture corresponded to a sharp increase in clinical severity. In particular, the respiratory situation was no longer manageable with oxygen supply or noninvasive ventilation strategies, and we were forced to perform an intubation with controlled mechanical ventilation. 


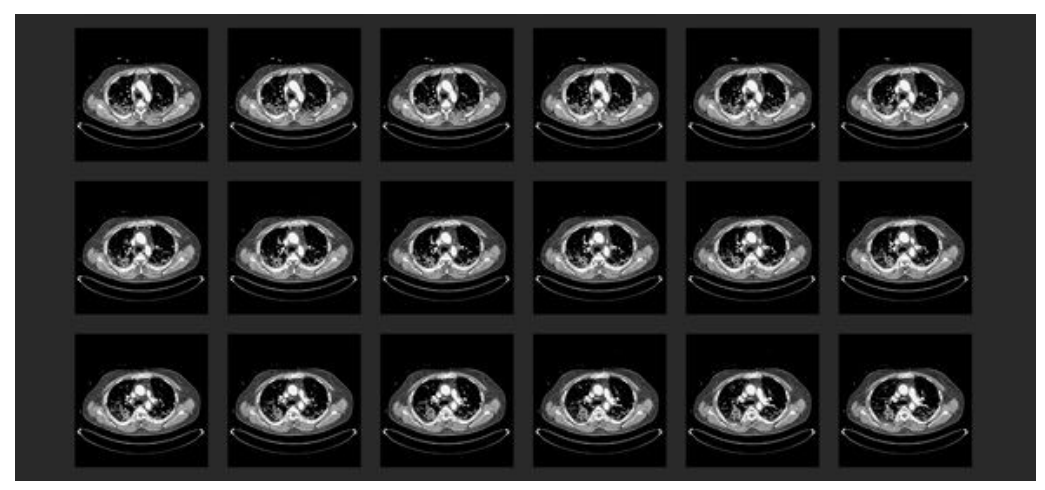

\section{Figure 4}

4 Chest CT scan with radiocontrast agent in the initial phase at the collaborating hospital: (1) A typical finding for COVID-19 pneumonia (according to the RSNA consensus 2020(45)). Multiple frequently described signs of COVID-19 pneumonia were displayed with an additional mediastinal lymphadenopathy. (2) Proof of a bilateral central pulmonary arterial emboly with concomitant occlusion of related segmental arteries. Pronounced right heart burdening with deviated septum and d-shape sign of the left ventricle. (3) Struma nodosa.

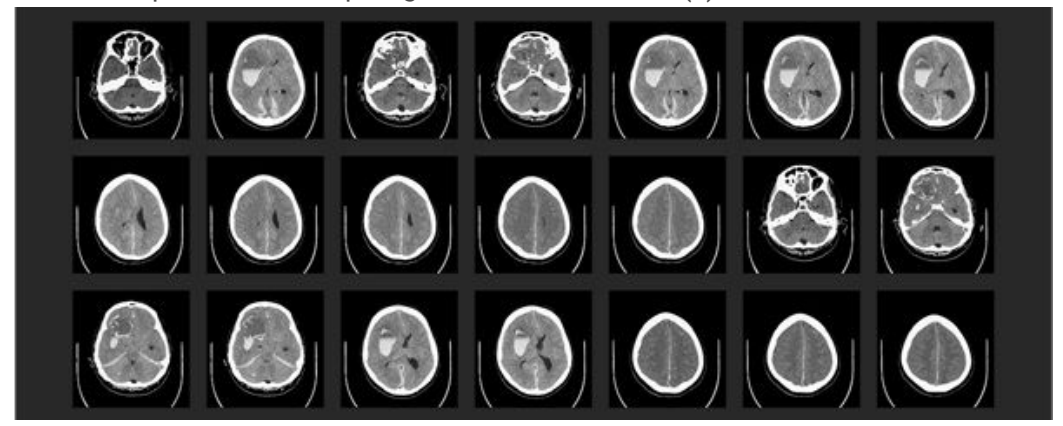

\section{Figure 5}

Emergency skull CT scan: (1) Large, fresh intraparenchymatous bleeding in right-hand frontoparietal lobe with global brain edema, midline shift, and entrapment within the tentorial slit. (2) Additional bleeds in the region of the right basal ganglia and the right cerebellar hemisphere. There was also subdural bleeding along the falx cerebri and above the tentorium cerebelli. 